\title{
Potential of Bioenergy Production from Microalgae
}

\author{
Thomas Driver • Amit Bajhaiya • Jon K. Pittman
}

Published online: 30 May 2014

(C) Springer International Publishing AG 2014

\begin{abstract}
There is increasing interest for sustainable bioenergy production to mitigate greenhouse gas emissions and reduce reliance on fossil fuels. Biofuel can be generated from a wide variety of feedstock types including algae. Algae are an attractive feedstock for the production of liquid and gaseous biofuels that do not need to directly compete with food production. However, both the sustainability and the economic viability of algal biofuels have been questioned, particularly with regard to high carbon and fertiliser input requirements, and high cultivation and production costs. Improved understanding and modifications at a biological level, of algal genetics, carbon storage metabolism, photosynthesis and algal physiology, have the potential for significant advances in algal biofuel feasibility. This is being driven by advances in genomic technologies to provide the potential for genetic and metabolic engineering, plus the development of high-throughput techniques for the screening of natural strains for suitable biofuel characteristics.
\end{abstract}

Keywords Algae biofuel · Biodiesel · Chlamydomonas . Forward genetics $\cdot$ Genetic manipulation $\cdot$ Hydrogen production $\cdot$ Life-cycle assessment $\cdot$ Lipid metabolism . Microalgae $\cdot$ Transcriptomics

\section{Introduction}

The use of fossil fuels as the primary source of energy is an unsustainable practice. Remaining oil reserve levels are unknown and the most optimistic estimations suggest oil reserves will last for a number of decades rather than centuries [1]. However, the environmental impacts of fossil fuel consumption have been widely demonstrated, with a significant

T. Driver $\cdot$ A. Bajhaiya $\cdot$ J. K. Pittman $(\bowtie)$

Faculty of Life Sciences, The University of Manchester, Michael

Smith Building, Oxford Road, Manchester M13 9PT, UK

e-mail: jon.pittman@manchester.ac.uk issue being the rising levels of atmospheric greenhouse gases (GHG) contributing to global climate change [2]. Therefore, there is increasing interest for sustainable alternatives such as bioenergy production to mitigate GHG emissions and reduce reliance on fossil fuels. In particular, there is a need for alternative liquid transportation fuels and it is for this reason that there has been significant development and commercialisation of biofuels in recent years. Biofuel can be generated from a wide variety of feedstock types, including various plant sources such as plant oils, sugars, starch and lignocellulose biomass from plant waste or energy crops; from animal oils and biomass; from organic waste; and from cultivated microorganisms [3, 4]. However, many food sources of biofuel feedstock such as wheat grain, corn starch and sugarcane, currently used extensively for commercial biofuel production, have been criticised because of their competition with food crops for agricultural land, water and nutrients $[5,6]$. The use of non-food 'energy crops' such as switchgrass and Jatropha curcas are being examined for biofuel production and may be promising for the future, but there may still be some issues of agricultural resource conflict [7]. In contrast, an alternative, potentially sustainable, biofuel feedstock source to be considered is algae. This review highlights some of the current challenges of biofuel generation, focussing mainly on microalgae, and will examine some of the recent research on biological understanding and genetic manipulation (GM) of microalgae, which may allow biofuel production from these organisms to be economically and sustainably viable in the future.

\section{Biofuel Products from Algae}

Algae are a diverse group of photosynthetic organisms with a range of unicellular to multicellular forms that are found in the ocean, freshwater bodies, on rock, soils and vegetation. They can be broadly divided into macroalgae, which include multicellular seaweeds, and microalgae, which are small 
unicellular algae, found in a wide variety of environments and comprising of many evolutionarily distinct organisms [8]. As autotrophic organisms, algae use solar energy and atmospheric $\mathrm{CO}_{2}$ to synthesise organic macromolecules including lipids and carbohydrates that can be converted into biofuel. Thus, algae have the potential to provide a theoretically carbonneutral fuel that requires minimal inputs. Some algae species can also be grown heterotrophically for higher productivity but then require carbon feed. A variety of scenarios for biofuel production from algae exist (Fig. 1). All types of algae can be used as a feedstock for the production of liquid and gaseous biofuels by thermochemical conversion methods such as pyrolysis, gasification and hydrothermal liquefaction [9]. Macroalgae accumulate very low quantities of oils, but are a good source of carbohydrate that could be converted into bioethanol or biomethane by biological conversion methods such as anaerobic digestion and fermentation. Microalgae are of particular interest because of the high yields of oil available in some strains, principally the glycerolipid triacylglycerol (TAG), that can be converted into biodiesel by transesterification $[3,10]$. High oil productivity of microalgae suggests that substantially less land area would be needed than for oil crops such as soybean or oilseed rape to produce the same quantity of biofuel [11]. In addition, microalgae are of interest because of the ability of some strains to produce hydrogen that could be used as a fuel source $[12 \cdot, 13]$. Finally, some microalgae, in particular Botryococcus braunii, can produce high concentrations of unusual triterpenic hydrocarbons that can be readily converted into fuels by conventional hydrocracking and distillation procedures [14].

\begin{tabular}{|c|c|c|c|c|c|}
\hline \multicolumn{6}{|c|}{ Strain selection } \\
\hline \multicolumn{2}{|c|}{ Microalgae } & \multicolumn{2}{|c|}{$\overline{\text { Macroalgae }}$} & \multicolumn{2}{|c|}{ Cyanobacteria } \\
\hline \multicolumn{6}{|c|}{ Water type } \\
\hline \multicolumn{2}{|c|}{ Freshwater } & \multicolumn{2}{|c|}{ Saltwater } & \multicolumn{2}{|c|}{ Wastewater } \\
\hline \multicolumn{6}{|c|}{ Cultivation method } \\
\hline Open ponds & \multicolumn{2}{|c|}{ Closed PBRs } & \multicolumn{2}{|c|}{ Hybrids } & Offshore \\
\hline \multicolumn{6}{|c|}{ Growth mode } \\
\hline \multicolumn{2}{|c|}{ Photoautotrophic } & \multicolumn{2}{|c|}{ Mixotrophic } & \multicolumn{2}{|c|}{ Heterotrophic } \\
\hline \multicolumn{6}{|c|}{ Harvesting method } \\
\hline Centrifugation & Filtering & Flocc & ation & Air flotation & Immobilisation \\
\hline \multicolumn{6}{|c|}{ Conversion process } \\
\hline $\begin{array}{l}\text { Biochemical } \\
\text { conversion }\end{array}$ & \multicolumn{2}{|c|}{$\begin{array}{c}\text { Thermochemical } \\
\text { conversion }\end{array}$} & \multicolumn{2}{|c|}{ Direct synthesis } & $\begin{array}{l}\text { Anaerobic } \\
\text { digestion }\end{array}$ \\
\hline \multicolumn{6}{|c|}{ Bioenergy product } \\
\hline $\begin{array}{l}\text { Esterified } \\
\text { biodiesel }\end{array}$ & Bioalcohol & \multicolumn{2}{|c|}{ Biogas } & Biohydrogen & $\begin{array}{l}\text { Drop-in } \\
\text { hydrocarbon }\end{array}$ \\
\hline
\end{tabular}

Fig. 1 The building blocks of algae biofuel production. The various scenarios for biofuel development from algae are represented. Many options are available with regard to algae type and strain choice, including both eukaryotic algae and prokaryotic cyanobacteria, the source of water for cultivation, cultivation method and mode of growth, the method of algae harvesting and the biofuel conversion process, which will partly determine whether a metabolite such as triacylglycerol is extracted from the algae, and will determine which type of biofuel will be generated
However, a challenge with this particular organism is its very slow growth and relatively inefficient oil extraction.

Overall, the significant attraction of algae as a biofuel feedstock is that it could be cultivated on non-agricultural land in open ponds, photobioreactors or in some cases under heterotrophic fermentative conditions. The cultivation could occur in conditions that do not need freshwater, as many strains can grow efficiently in saltwater or wastewater $[10$, 15]. Furthermore, algae productivity could be enhanced through the exploitation of waste $\mathrm{CO}_{2}$ such as from flue gas sources [16]. These various cultivation and biofuel generation scenarios (Fig. 1) mean that estimations of commercial-scale algal biofuel production (algal crude oil) can vary widely, potentially from 8,000 to $140,000 \mathrm{~L} \mathrm{ha}^{-1} \mathrm{y}^{-1}[11,17]$. The commercial production of algae biofuel is still limited, particularly from autotrophic open pond cultivation, but appears to be expanding for heterotrophic cultivation. For example, the US-based company Solazyme produces algal oil from heterotrophic cultivation for biodiesel production, and produced over 500,000 L in 2010-2011, and plans to have production facilities for millions of litres of oil by 2015 [15, 18]. However, despite the significant research interest and private investment in algae biofuel generation over the last decade, both the sustainability and the economic viability of algal biofuels have been questioned.

\section{Challenges for Sustainable and Economically Viable Algal Biofuel Production}

Life-cycle assessment (LCA) has been used to predict the potential environmental benefits and implications of largescale algal biofuel production. A wide variety of LCA studies have now been published, mostly for the analysis of biodiesel production from microalgae. However, the predictions and conclusions from these studies have been highly variable and unable to be directly compared, partly because of the wide variation in microalgal cultivation, harvesting and processing methods that can be modelled (Fig. 1), but also because of different LCA methods, hypotheses and parameters being used $[19 \bullet, 20 \bullet, 21]$. For example, with regard to modelled environmental impacts of biofuel production, a comparison of 15 LCA studies found that there was significant variation in GHG emission balance results as a result of different modelling methodologies and assumptions, with some showing a negative environmental impact while others are positive [20•]. Furthermore, while most of these studies assess GHG emission balance, few assess other impacts such as eutrophication or land use. One approach to overcome these comparison issues is to normalise LCA results. A recent analysis of six normalised LCA studies suggests that microalgae biodiesel production can provide a positive GHG emission balance and positive energy balance, but at values that 
are equivalent to those of conventional crop-derived biodiesel [19॰]. The overall consensus indicates that algal biofuels can be beneficial in terms of GHG emissions. For example, a recent analysis of a pilot-scale microalgae open-pond and hydrothermal liquefaction facility run by Sapphire Energy indicated that such a process would provide lower GHG emissions than petroleum fuels and corn ethanol but with a downside of significantly lower energy return on investment than petroleum fuels [22].

LCA studies have also predicted substantial negative environmental impacts, notably a high freshwater use and nutrient (fertiliser) requirement. For example, if large-scale algal biofuel production was implemented to produce $5 \%$ of the current transportation fuel demand of the USA, the use of 12 million $t$ of phosphorus (P), 6-15 million $t$ of nitrogen $(\mathrm{N})$ and 3.1-3650 $\mathrm{L}$ of freshwater per $\mathrm{L}$ biofuel has been estimated $[23,24]$. The variation in water requirement varies depending on whether freshwater or marine algae are cultivated, indicating that freshwater cultivation is clearly unsustainable. However, such a fertiliser requirement is clearly untenable as it would directly compete with fertiliser requirements for food production, while the increasing scarcity of $\mathrm{P}$ fertiliser and the high GHG footprint of $\mathrm{N}$ fertiliser would be a further concern $[25,26]$. The suggested use of wastewater to partly mitigate freshwater use may also allow recycling of waste $\mathrm{P}$ and $\mathrm{N}$ nutrients, which are abundant in many municipal wastewater sources. Furthermore, the cost benefit of using the algae for remediating wastewater may allow a reduction in biomass production costs [27-29]. Wastewater can be a challenging and toxic environment for algal cultivation and requires the development of strains that can grow successfully [30-32]. However, there is a limited supply of wastewater, and nutrients from this source will not be sufficient as an alternative to fertiliser [33, 34]. Therefore, wastewater cultivation of algae should be limited to remediation applications and any energy return used to reduce waste treatment costs.

The current cost of biofuel production from algae is hard to determine, particularly as there are no commercial-scale production facilities. A recent estimate of biodiesel cost has a range of US\$0.42-0.97 $\mathrm{L}^{-1}$, which was felt by the authors of the study to be close to commercial reality [35]. Despite a wide number of start-up companies and larger multi-national corporations investing in algal fuels over the last decade [34], there has been no evidence of a significant reduction in cost, with one report that it cost Solazyme approximately US\$17 L${ }^{1}$ to produce biodiesel using heterotrophic cultivation methods [15]. However, the current low cost of petroleum fuels coupled with high projected costs of algal biofuel production based on existing technology gives a consensus that these fuels are non-viable commercially in the short term [34]. There are a variety of factors contributing to high production costs [34]. These include low biomass productivity particularly for open pond-based cultivation [36] and where $\mathrm{CO}_{2}$ input is low or inconsistent [37], input costs including fertiliser and carbon if algae is grown heterotrophically [34], high cultivation infrastructure and maintenance costs particularly for photobioreactor-based cultivation, and high harvesting, product extraction and processing costs [38]. Clearly, there are many technological hurdles to overcome and it is therefore unsurprising that the current short- to medium-term focus with commercial algal biotechnology is for the production of high-value nutraceutical, pharmaceutical and cosmetic products such as beta-carotene and omega-3 fatty acids rather than biofuel [39].

\section{Biological Solutions for Algal Biofuel Advances}

While improvements are being made to cultivation technology, energy-efficient harvesting methods and oil extraction procedures, improved understanding and modifications at a biological level have the potential for significant advances in algal biofuel feasibility. It has been argued that a development of algae that is analogous to the breeding and domestication of crops is required to really exploit the potential of these organisms for both biofuel usage and other applications [40]. For biofuel development, this requires improved understanding of algal genetics, lipid metabolism, photosynthesis and algal physiology to attempt to improve algal growth and biomass productivity, improve light harvesting and $\mathrm{CO}_{2}$ use efficiency for photosynthesis, improve oil productivity and extraction, improve nutrient use efficiency and improve cell autoflocculation for more efficient harvesting. Advances in genomics technologies and genetic transformation provide the potential to manipulate algae genetically [11, 40-43]. However, in addition to the use of genetic and metabolic engineering, it is essential to make use of the significant natural variation and diversity that exists within algal populations, and to consider non-GM methods.

\section{Genomic Approaches for Gene Discovery}

Potential improvements of biofuel characteristics of algae through genetic engineering depend on the identification of target genes. The continuing availability of sequenced algal genomes [41, 43] and recent advancements in transcriptomic sequencing technology, particularly with the model microalga Chlamydomonas reinhardtii, have increased the scope of our genetic understanding of microalgae [44-46], not only allowing the identification of key genes, but also for finding novel genetic regulators [47॰], which could be targets for GM.

There is strong interest in understanding carbon metabolism and its regulation in context to lipid (specifically TAG) accumulation in microalgae [48, 49]. Our understanding of carbon storage metabolism pathways in chlorophyte microalgae, in particular $C$. reinhardtii has expanded greatly 
in recent years through the use of comparative genomics and transcriptomics, and the reader is directed to recent reviews for a detailed description of lipid and starch metabolism in microalgae $\left[40,41,50^{\bullet}\right]$. The concentration of TAG accumulated by algal cells has been shown to significantly increase under environmental stress, with $\mathrm{N}$ starvation considered the best trigger for TAG accumulation, but the starvation of nutrients such as sulphur (S), P, zinc, iron and salt stress also promotes both TAG and starch biosynthesis in algae [51, 52, $53 \bullet \bullet, 54,55]$. While manipulation of nutrient deficiency in cultivation conditions can be used to enhance lipid productivity in mass cultures [56], the identification of these stresses has other benefits. Such consistent TAG and starch biosynthesis inducers such as $\mathrm{N}$ starvation are an excellent tool to understand the transcriptional and metabolic changes that occur within the cell during the onset of carbon storage. For example, this has been proved as a strong tool for the identification of some of key lipid metabolism enzymes [40, 44, 47•, 53••].

Starch-less mutants of $C$. reinhardtii (such as sta6) produce more lipid than wild-type strains because of an increased carbon pool [57]. A transcriptomic comparison of sta6 and wild-type C. reinhardtii under $\mathrm{N}$-starved conditions examined the effect of redirecting carbon from starch biosynthesis toward TAG accumulation, and found several transcriptional changes of key ratelimiting carbon metabolism enzymes, giving a hope of finding a key regulator for carbon flux in N-limited conditions [53••]. Despite sta 6 being unable to produce significant starch, various starch biosynthesis enzymes are up-regulated in response to $\mathrm{N}$ starvation during early stages of growth, suggesting that starch synthesis is a programmed response to $\mathrm{N}$ starvation regardless of output. When grown under $\mathrm{N}$ starvation and boosted with additional exogenous carbon in the form of acetate, many enzymes involved in acetate metabolism increased highly in sta6, along with an acyl-CoA:diacylglycerol acyltransferase (DGAT), a glycerol-3-phosphate dehydrogenase, both key enzymes in TAG synthesis, and two lipases [58•]. This coordinated increase in acetate metabolism in sta6 suggests an up-regulated increase in acetate use and carbon flux for the generation of lipid storage in sta6, making this carbon flux pathway a potential regulator of TAG biosynthesis in N-starved conditions. Furthermore, the study highlights up-regulated enzymes, such as the DGAT, as interesting GM targets for enhanced storage metabolite synthesis.

Similar transcriptomic studies have been performed under various nutrient starvation conditions to indicate key genes in carbon storage metabolism [44, 45, 47•,59•]. These include two DGATs, and a phospholipid diacylglycerol acyltransferase, another key TAG biosynthesis enzyme, plus a putative transcriptional regulator of $\mathrm{N}$-induced lipid metabolism, called NRR1, which when mutated causes a reduction in $\mathrm{N}$ starvation-induced TAG accumulation [47•]. S starvation is also of interest as this stress can not only induce the accumulation of TAG and starch, and correlated up-regulation of specific lipid metabolism genes [45], but can also induce the production of hydrogen [13]. Transcriptomic analysis of C. reinhardtii undergoing hydrogen production following $\mathrm{S}$ starvation shows substantial remodelling of primary metabolism, but also the identification of potential regulatory genes that could be future targets for manipulation to increase hydrogen production in this microalgae [59•].

\section{Targeted Metabolic Engineering}

Advances in our understanding of microalgal lipid metabolism, and of the genes encoding these pathways, such as from transcriptomic analyses, provides the possibility of developing economically viable strains of microalgae for biodiesel through targeted metabolic engineering (Table 1). Manipulation of microalgae requires the ability to stably transform the organism with a transgene, which until recently has been challenging for all but a select few species [41], and even though nuclear genome transformation is efficient in a species such as C. reinhardtii, stable expression can be variable [60] and targeted nuclear genome manipulation has not been demonstrated. However, of particular interest was the recent observation that nuclear genome insertion in Nannochloropsis can be achieved by homologous recombination [61•], thus allowing precise transgene targeting. It is expected that the genetic toolbox for microalgae will expand even further in coming years. In higher plants, a number of advanced genetic tools have been developed. These include synthetic promoters, tuneable transcription factors, genomeediting tools and site-specific recombinases [62]. One such method, using zinc-finger nucleases for the specific modification of endogenous nuclear genes has already been optimised for C. reinhardtii [63•]. With such microalgal genetic techniques continuing to progress, and the understanding of microalgal lipid metabolism developing rapidly, metabolic engineering could prove invaluable in the development of economically viable algal biofuels.

One enzyme family that has been identified as potentially the most promising target for over-expression are the DGATs [37, 64, 65]. DGATs have been studied considerably in higher plants and can be categorised into three subgroups: Type-1, Type- 2 and Type-3, and they catalyse the final committed step in TAG biosynthesis [40]. The $C$. reinhardtii Type-2 DGAT genes have been shown in several transcriptomic studies to be up-regulated when TAG accumulation is induced under stress conditions [44, 47•, 66]. Furthermore, DGATs have been suggested to be the primary enzyme for de novo TAG biosynthesis in all organisms studied so far [67]. However, despite the evidence suggesting that Type-2 DGATs are key players in TAG accumulation, overexpression of these genes in $C$. reinhardtii had no effect on the levels of TAG or total lipids [68•]. The Type-2 DGAT may therefore be a downstream response to another enzyme, and there may be a bottleneck in carbon flux further back in the TAG biosynthesis pathway. This highlights the potential pitfalls 
Table 1 Summary of selected genetic approaches for the manipulation of microalgae for improved biofuel characteristics

\begin{tabular}{|c|c|c|c|c|c|c|}
\hline Trait & Process modified & Target & Method & Outcome & Species & Reference \\
\hline Lipid yield & TAG catabolism & $\begin{array}{l}\text { Lipase (Thaps3 } \\
\text { 264297) }\end{array}$ & $\begin{array}{l}\text { RNA interference } \\
\text { and antisense }\end{array}$ & $\begin{array}{l}\text { 2.4-3.3 fold increase } \\
\text { (exponential } \\
\text { growth); } 3.2-4.1 \text { fold } \\
\text { increase (after } \mathrm{Si} \\
\text { starvation) }\end{array}$ & $\begin{array}{l}\text { Thalassiosira } \\
\text { pseudonana }\end{array}$ & {$[72 \bullet \bullet]$} \\
\hline Lipid yield & TAG synthesis & Type-2 DGAT & Over-expression & $35 \%$ increase & $\begin{array}{l}\text { Phaeodactylum } \\
\text { tricornutum }\end{array}$ & {$[70]$} \\
\hline $\begin{array}{l}\text { Lipid yield and } \\
\text { productivity }\end{array}$ & TAG synthesis & Unknown & $\begin{array}{l}\text { Heavy-ion irradiation } \\
\text { mutagenesis }\end{array}$ & $\begin{array}{c}14 \% \text { increase (TAG } \\
\text { content); } 28 \% \\
\text { increase (lipid } \\
\text { productivity) }\end{array}$ & $\begin{array}{l}\text { Nannochloropsis } \\
\text { oceanica }\end{array}$ & [89] \\
\hline $\begin{array}{l}\text { Lipid yield and } \\
\text { productivity }\end{array}$ & $\begin{array}{l}\text { Unknown, maybe } \\
\text { TAG catabolism }\end{array}$ & $\begin{array}{l}\text { Unknown but including } \\
\text { long-chain fatty acid } \\
\text { ligase }\end{array}$ & Ultraviolet mutagenesis & $\begin{array}{l}80 \% \text { increase (TAG } \\
\text { productivity) }\end{array}$ & Tisochrysis lutea & {$[91,92 \bullet]$} \\
\hline Hydrogen production & Hydrogenase $\mathrm{O}_{2}$ sensitivity & PsbO (PSII) & RNA interference & 10 fold increase & Chlorella sp. DT & [74] \\
\hline Hydrogen production & Thylakoid proton gradient & PGRL1 & $\begin{array}{l}\text { DNA insertional } \\
\text { mutagenesis } \\
\text { (random screen) }\end{array}$ & 3 fold increase & $\begin{array}{l}\text { Chlamydomonas } \\
\text { reinhardtii }\end{array}$ & [75] \\
\hline Hydrogen production & $\begin{array}{l}\text { State transitions; increased } \\
\text { PSII stability }\end{array}$ & STM6 & $\begin{array}{l}\text { DNA insertional } \\
\text { mutagenesis } \\
\text { (random screen) }\end{array}$ & 5-13 fold increase & C. reinhardtii & {$[76 \bullet]$} \\
\hline Hydrogen production & $\begin{array}{l}\text { Photosynthetic efficiency; } \\
\text { reduced antenna size }\end{array}$ & $\begin{array}{l}\text { LHCBM1, 2, } 3 \text { light } \\
\text { harvesting } \\
\text { complex proteins }\end{array}$ & RNA interference & 2 fold increase & C. reinhardtii & [77] \\
\hline $\begin{array}{l}\text { Growth rate (under } \\
\text { high light) }\end{array}$ & $\begin{array}{l}\text { Reduced antenna size; } \\
\text { reduced photo- } \\
\text { inhibition }\end{array}$ & $\begin{array}{l}\text { All light-harvesting } \\
\text { complex proteins }\end{array}$ & RNA interference & $\begin{array}{c}45 \% \text { increase } \\
\text { after } \sim 28 \mathrm{~h}\end{array}$ & C. reinhardtii & [78] \\
\hline
\end{tabular}

$D G A T$ diacylglycerol acyltransferase, PSII photosystem II, TAG triacylglycerol

of the metabolic engineering of intricate metabolic pathways in complex organisms. In contrast, one of the four Type-2 DGAT isoforms and a Type-3 DGAT from the diatom Phaeodactylum tricornutum were able to restore TAG biosynthesis when expressed in a TAG-deficient yeast strain [69, 70]. More recently, over-expression of a Type-2 DGAT in P. tricornutum led to a $35 \%$ increase in neutral lipid accumulation [71]. However, it should be noted that only one over-expression line was presented in this study.

An alternative approach has been taken with another diatom species to reduce TAG catabolism. A TAG lipase was knocked down in Thalassiosira pseudonana, which led to a considerable increase in TAG content without any adverse effects on growth [72••] (Table 1). This result is extremely promising as it confirms that it is possible to increase TAG yields without negative effects on growth, and the findings also provide hope that further improvements in TAG yields can be made through manipulating other target genes. It is also possible that TAG yields may be increased further by using a combined approach of reducing TAG catabolism and increasing TAG anabolism simultaneously.

In addition to manipulating lipid metabolism, various transgenic approaches have been used to manipulate hydrogen production, mainly through RNA interference- or DNA insertional mutagenesis-based gene silencing [73] (Table 1). Some of these approaches include reducing the oxygen sensitivity of hydrogenases, such as through the mutation of photosystem II (PSII) components [74], manipulating the thylakoid proton gradient by mutation of cyclic electron flow components [75], manipulating the photosynthetic state transition by improved PSII stability by mutation of a state transition regulator [76 ${ }^{\circ}$ ] or increasing the photosynthetic efficiency for increased hydrogen production by decreasing the chlorophyll antenna size of the photosystems by mutation of light-harvesting complex proteins to increase the light use efficiency [77]. Such manipulation of antenna size is not just of benefit for hydrogen production and has been shown to reduce photo-inhibition and increase the growth rate under high light conditions [78].

\section{Natural Algal Strain Diversity and Non-genetic Manipulation Methods}

Whilst a considerable focus has been placed upon GM approaches to increase oil yields and improve biomass productivity, it is important not to forget the substantial possibilities that non-GM approaches provide, in particular because of the regulatory, commercial and ethical constraints of GM organisms, plus the potential environmental safety implications. A challenge with any GM strain is containment, both to prevent 
loss into the environment and mitigation of unknown consequences including the risk of transgene flow, and the loss of the GM strain in the mass culture through contamination with non-GM strains or predation. A mechanistic model was used to simulate the consequences of GM strains with reduced photosystem antenna size and modified photosynthetic efficiency, which would be expected to perform better in mass cultivation conditions. It was predicted that such strains would have reduced evolutionary fitness and be disadvantaged in competition with non-GM strains [79]. However, modelling of a GM strain with various biofuel optimisation traits, including growth rate, respiration, and nutrient use, suggests that such a strain will less likely be grazed upon by a predator than a nonGM strain and therefore would have increased risk of generating harmful algal blooms in natural environments [80•].

Screening natural strains for suitable characteristics including high biomass productivity or oil yield either from culture collections or from natural environments (bioprospecting) is another approach. Only a handful of microalgal species are being characterised in depth for biofuel development or used as 'model' species, including Nannochloropsis sp., Dunaliella sp., Chlorella sp., C. reinhardtii, B. braunii, T. pseudonana, P. tricornutum and Tisochrysis lutea. In contrast, many thousands of microalgal species and strains are likely to exist with desired characteristics. Even through screening of small numbers of strains $(<100)$, it is apparent that there are marked variations in total lipid yield, fatty acid characteristics and growth rate $[49,81]$. Bioprospecting studies are continuing to identify useful natural strains [82-84]. Ideally, such studies depend on accurate but high-throughput screening techniques such as flow cytometry or vibrational spectroscopy that can rapidly screen metabolite characteristics [84-87], but also genomics techniques for strain identification and cryopreservation methods [42]. Characteristics from natural strains could be used to improve and combine particular characteristics in commercially useful biofuel strains, such as through markerassisted breeding. Quantitative trait loci (QTLs) and rare alleles associated with a desirable trait and could be bred into commercial strains of microalgae. Although this approach has not been studied extensively in algae, a method such as EcoTilling [88] could be used to identify the naturally occurring alleles of, for example, lipid metabolism genes. Such preferred alleles could be subsequently bred into commercial strains of microalgae to obtain high levels of TAG accumulation. In addition, genetic information from natural strains could be an important resource for GM of commercial strains.

Another approach of strain modification that is often not regarded as GM, because transgenic material is not involved, is mutagenesis screening (forward genetics) performed using an exogenous mutagen such as ultraviolet light. Mutagenesis screens could generate commercial algal strains without the need for a targeted approach, and could also identify novel genes previously unknown to be involved in lipid metabolism. Novel methods of mutagenesis [89] and screening [87, 90, 91] have been recently developed that could be used across a large number of oleaginous microalgal species, including less widely studied species, to improve characteristics for biofuel production. One study, using heavy-ion irradiation mutagenesis identified a Nannochloropsis oceanica mutant with a $28 \%$ increase in lipid productivity and improved growth characteristics [89]. In another study, a strain of $T$. lutea was mutated by two rounds of ultraviolet treatment and flow cytometry selection to yield an $80 \%$ increase in neutral lipid productivity [91]. Subsequent analysis of this strain by transcriptome sequencing found that 291 transcripts were differentially expressed, 165 of which contained a single nucleotide polymorphism. Although the majority of these transcripts were not known lipid metabolism genes, one encoded a putative long-chain fatty acid ligase required for the esterification of free fatty acids, which could potentially cause a defect in lipid catabolism [92•].

\section{Conclusions}

It is clear that there is a long way to go before the commercialscale production of biofuels from algal feedstock will be a reality. Although production of algal biodiesel via heterotrophic fermentation can be performed on a commercial basis [18], there are doubts regarding the economic sustainability and the scalability of this method of production. There are currently a large number of factors that have to be overcome both to improve the technoeconomic feasibility of the process and to alleviate some of the sustainability concerns, particularly with regard to the excessively high amounts of fertilisers that are estimated to be required. However, progress in the identification and development of new strains, particularly of microalgae, that are better tailored for the mass cultivation of biofuel products is promising. In addition, some of the significant improvements in our understanding of the fundamental biological processes of algae and the proof-ofconcept developments through genetic manipulation are providing positive outcomes. In the meantime, commercial use of algae will likely increase for the development of high-value products and applications, and knowledge gained from this experience may be beneficial to future cultivation of algae for fuel products.

Although basic research should continue to be directed towards strain development, not just for improved biomass production and oil yield, but for more efficient input (e.g. fertiliser) use, the use of such strains, particularly if they are generated by GM or synthetic biology technologies, must controlled by appropriate regulation. There is a strong potential that useful genetic mutation identified in the laboratory can be transferred into commercial strains using non-GM approaches such as ultraviolet mutagenesis and tilling, and therefore such non-GM strains would be more attractive to industry. However, potential environmental impacts of all novel strains must be rigorously assessed. Research is also needed to assess the potential 
applications of by-products from algal biomass following extraction of biofuel products, to further exploit the economic value of the biomass (biorefining of algae biomass). For example, following extraction of algal oil, some of the residues may be used for the isolation of useful chemicals or used as a biofertiliser or animal feed, if the residue biomass is nutrient rich. Alternatively, the remaining biomass may be further converted into bioenergy products such as via thermochemical conversion or anaerobic digestion. The choice of biomass use and the development of particular products will be largely determined by market price. However, robust LCA and techno-economic analysis must also be further developed and used to make sure that the future algal biofuel and biotechnology industries are both economically and environmentally sustainable. All of these developments must be evaluated under scaled-up conditions to demonstrate commercial viability, and there are many engineering challenges to be overcome to allow efficient, low-cost and low-energy algal cultivation on a sufficiently large scale. Finally, there needs to be both industry and governmental policies in place to support the use of algae as a feedstock for bioenergy and transportation fuels, not just through public funding to support the various research and development needs, but potential legislative or tax incentives for encouraging the commercial development and use of algal-derived fuels. The development and implementation of international biofuel standards will also be important in the adoption of biofuels in general, and the acceptance of algal-derived biofuels in particular. Currently, crop-derived bioethanol from Brazil and the USA accounts for the majority of the global biofuel sector. Ultimately, the diversification of biofuel sources is important to improve energy security and environmental sustainability, and algae biofuel could be a major component in a diverse bioenergy sector.

\section{Compliance with Ethics Guidelines}

Conflict of Interest Thomas Driver, Amit Bajhaiya and Jon K. Pittman declare no conflict of interest.

Human and Animal Rights and Informed Consent The manuscript does not contain clinical studies or patient data.

\section{References}

Papers of particular interest, published recently, have been highlighted as:

- Of importance

-. Of major importance

1. Owen NA, Inderwildi OR, King DA. The status of conventional world oil reserves: hype or cause for concern? Energ Policy. 2010;38(8):4743-9.

2. Raupach MR, Marland G, Ciais P, Le Quere C, Canadell JG, Klepper $\mathrm{G}$, et al. Global and regional drivers of accelerating $\mathrm{CO}_{2}$ emissions. Proc Natl Acad Sci U S A. 2007;104(24):10288-93.
3. Demirbas A. Biofuels securing the planet's future energy needs. Energ Convers Manag. 2009;50(9):2239-49.

4. Chhetri AB, Islam MR. Towards producing a truly green biodiesel. Energy Sources Part A. 2008;30(8):754-64.

5. Duer H, Christensen PO. Socio-economic aspects of different biofuel development pathways. Biomass Bioenergy. 2010;34(2):23743.

6. Ewing M, Msangi S. Biofuels production in developing countries: assessing tradeoffs in welfare and food security. Environ Sci Policy. 2009;12(4):520-8.

7. Cai X, Zhang X, Wang D. Land availability for biofuel production. Environ Sci Technol. 2011;45(1):334-9.

8. Tirichine L, Bowler C. Decoding algal genomes: tracing back the history of photosynthetic life on Earth. Plant J. 2011;66(1):45-57.

9. Jin B, Duan P, Xu Y, Wang F, Fan Y. Co-liquefaction of micro- and macroalgae in subcritical water. Bioresour Technol. 2013;149:10310.

10. Brennan L, Owende P. Biofuels from microalgae: a review of technologies for production, processing, and extractions of biofuels and co-products. Renew Sust Energ Rev. 2010;14(2):557-77.

11. Georgianna DR, Mayfield SP. Exploiting diversity and synthetic biology for the production of algal biofuels. Nature. 2012;488(7411):329-35.

12. Hwang J-H, Kim H-C, Choi J-A, Abou-Shanab RAI, Dempsey BA, Regan JM, et al. Photoautotrophic hydrogen production by eukaryotic microalgae under aerobic conditions. Nat Commun. 2014;5: 3234. A very intriguing observation that $\mathrm{H}_{2}$ can be produced under aerobic conditions in contrast to the strictly anaerobic conditions that were previously thought to be required.

13. Melis A, Zhang LP, Forestier M, Ghirardi ML, Seibert M. Sustained photobiological hydrogen gas production upon reversible inactivation of oxygen evolution in the green alga Chlamydomonas reinhardtii. Plant Physiol. 2000;122(1):127-35.

14. Banerjee A, Sharma R, Chisti Y, Banerjee UC. Botryococcus braunii: a renewable source of hydrocarbons and other chemicals. Crit Rev Biotechnol. 2002;22(3):245-79.

15. Menetrez MY. An overview of algae biofuel production and potential environmental impact. Environ Sci Technol. 2012;46(13): 7073-85.

16. Doucha J, Straka F, Livansky K. Utilization of flue gas for cultivation of microalgae (Chlorella sp.) in an outdoor open thin-layer photobioreactor. J Appl Phycol. 2005;17(5):403-12.

17. Singh A, Nigam PS, Murphy JD. Renewable fuels from algae: an answer to debatable land based fuels. Bioresour Technol. 2011;102: $10-6$.

18. Lane J. Solazyme: Biofuels digest's 2014 5-minute guide. Biofuels Digest. 2014. http://www.biofuelsdigest.com/bdigest/2014/02/17/ solazyme-biofuels-digests-2014-5-minute-guide/. (Accessed 12 May 2014)

19. Liu X, Clarens AF, Colosi LM. Algae biodiesel has potential despite inconclusive results to date. Bioresour Technol. 2012;104:803-6. An attempt to compare multiple LCA studies by using a normalisation technique. More comparisons of LCAs are needed to generate confident conclusions of biofuel technologies and approaches.

20. Collet P, Spinelli D, Lardon L, Helias A, Steyer J-P, Bernard O. Life-cycle assessment of microalgal-based biofuels. Biofuels from algae. Amsterdam: Elsevier; 2014. A thorough evaluation and comparison of LCA studies. A good discussion of some of the pitfalls and suggestions for future good practice.

21. Sills DL, Paramita V, Franke MJ, Johnson MC, Akabas TM, Greene $\mathrm{CH}$, et al. Quantitative uncertainty analysis of life cycle assessment for algal biofuel production. Environ Sci Technol. 2012;47(2):687-94.

22. Liu X, Saydah B, Eranki P, Colosi LM, Mitchell BG, Rhodes $J$, et al. Pilot-scale data provide enhanced estimates of the life cycle energy and emissions profile of algae biofuels produced 
via hydrothermal liquefaction. Bioresour Technol. 2013;148: 163-71.

23. Pate R, Klise G, Wu B. Resource demand implications for US algae biofuels production scale-up. Appl Energ. 2011;88(10):3377-88.

24. Yang J, Xu M, Zhang X, Hu Q, Sommerfeld M, Chen Y. Life-cycle analysis on biodiesel production from microalgae: water footprint and nutrients balance. Bioresour Technol. 2011;102(1):159-65.

25. Cordell D, Rosemarin A, Schroder JJ, Smit AL. Towards global phosphorus security: a systems framework for phosphorus recovery and reuse options. Chemosphere. 2011;84(6):747-58.

26. Gilbert P, Alexander S, Thornley P, Brammer J. Assessing economically viable carbon reductions for the production of ammonia from biomass gasification. J Clean Prod. 2014;64:581-9.

27. Lundquist TJ, Woertz IC, Quinn NWT, Benemann JR. A realistic technology and engineering assessment of algae biofuel production. Berkeley: Energy Biosciences Institute, University of California; 2010.

28. Pittman JK, Dean AP, Osundeko O. The potential of sustainable algal biofuel production using wastewater resources. Bioresour Technol. 2011;102(1):17-25.

29. Craggs RJ, Heubeck S, Lundquist TJ, Benemann JR. Algal biofuels from wastewater treatment high rate algal ponds. Water Sci Technol. 2011;63(4):660-5.

30. Osundeko O, Davies H, Pittman JK. Oxidative stress-tolerant microalgae strains are highly efficient for biofuel feedstock production on wastewater. Biomass Bioenergy. 2013;56:284-94.

31. Osundeko O, Pittman JK. Implications of sludge liquor addition for wastewater-based open pond cultivation of microalgae for biofuel generation and pollutant remediation. Bioresour Technol. 2014; 152:355-63.

32. Li Y, Chen Y-F, Chen P, Min M, Zhou W, Martinez B, et al. Characterization of a microalga Chlorella sp. well adapted to highly concentrated municipal wastewater for nutrient removal and biodiesel production. Bioresour Technol. 2011;102(8):5138-44.

33. Orfield ND, Keoleian GA, Love NG. A GIS based national assessment of algal bio-oil production potential through flue gas and wastewater co-utilization. Biomass Bioenergy. 2014;63:76-85.

34. Chisti Y. Constraints to commercialization of algal fuels. J Biotechnol. 2013;167(3):201-14.

35. Nagarajan S, Chou SK, Cao S, Wu C, Zhou Z. An updated comprehensive techno-economic analysis of algae biodiesel. Bioresour Technol. 2013;145:150-6.

36. Chisti Y. Raceways-based production of algal crude oil. Microalgal Biotechnology: Potential and Production. Berlin: de Gruyter; 2012.

37. Chisti Y. Biodiesel from microalgae. Biotechnol Adv. 2007;25(3): 294-306.

38. Molina Grima E, Belarbi EH, Acien Fernandez FG, Robles Medina A, Chisti Y. Recovery of microalgal biomass and metabolites: process options and economics. Biotechnol Adv. 2003;20(7-8): 491-515.

39. Guedes AC, Amaro HM, Malcata FX. Microalgae as sources of high added-value compounds: a brief review of recent work. Biotechnol Prog. 2011;27(3):597-613.

40. Merchant SS, Kropat J, Liu BS, Shaw J, Warakanont J. TAG, You're it! Chlamydomonas as a reference organism for understanding algal triacylglycerol accumulation. Curr Opin Biotechnol. 2012;23(3):352-63.

41. Radakovits R, Jinkerson RE, Darzins A, Posewitz MC. Genetic engineering of algae for enhanced biofuel production. Eukaryot Cell. 2010;9(4):486-501.

42. Larkum AWD, Ross IL, Kruse O, Hankamer B. Selection, breeding and engineering of microalgae for bioenergy and biofuel production. Trends Biotechnol. 2012;30(4):198-205.

43. Day JG, Slocombe SP, Stanley MS. Overcoming biological constraints to enable the exploitation of microalgae for biofuels. Bioresour Technol. 2012;109:245-51.
44. Miller R, Wu GX, Deshpande RR, Vieler A, Gartner K, Li XB, et al. Changes in transcript abundance in Chlamydomonas reinhardtii following nitrogen deprivation predict diversion of metabolism. Plant Physiol. 2010;154(4):1737-52.

45. Gonzalez-Ballester D, Casero D, Cokus S, Pellegrini M, Merchant SS, Grossman AR. RNA-seq analysis of sulfur-deprived Chlamydomonas cells reveals aspects of acclimation critical for cell survival. Plant Cell. 2010;22(6):2058-84.

46. Fang W, Si Y, Douglass S, Casero D, Merchant SS, Pellegrini M, et al. Transcriptome-wide changes in Chlamydomonas reinhardtii gene expression regulated by carbon dioxide and the $\mathrm{CO}_{2}$-concentrating mechanism regulator CIA5/CCM1. Plant Cell. 2012;24(5): 1876-93.

47. Boyle NR, Page MD, Liu BS, Blaby IK, Casero D, Kropat $\mathrm{J}$, et al. Three acyltransferases and nitrogen-responsive regulator are implicated in nitrogen starvation-induced triacylglycerol accumulation in Chlamydomonas. J Biol Chem. 2012;287(19):15811-25. The first identification of an $N$ starvation regulator of lipid metabolism.

48. Courchesne NMD, Parisien A, Wang B, Lan CQ. Enhancement of lipid production using biochemical, genetic and transcription factor engineering approaches. J Biotechnol. 2009;141(1-2):3141.

49. $\mathrm{Hu} \mathrm{Q}$, Sommerfeld $\mathrm{M}$, Jarvis E, Ghirardi M, Posewitz M, Seibert M, et al. Microalgal triacylglycerols as feedstocks for biofuel production: perspectives and advances. Plant J. 2008;54(4):621-39.

50. Johnson X, Alric J. Central carbon metabolism and electron transport in Chlamydomonas reinhardtii: metabolic constraints for carbon partitioning between oil and starch. Eukaryot Cell. 2013;12(6): 776-93. A detailed review of the current understanding of carbon metabolism in the algae Chlamydomonas including a discussion of the role of photosynthesis and the electron transport chain on carbohydrate and lipid metabolism.

51. Breuer G, Lamers PP, Martens DE, Draaisma RB, Wijffels RH. The impact of nitrogen starvation on the dynamics of triacylglycerol accumulation in nine microalgae strains. Bioresour Technol. 2012;124:217-26.

52. Matthew T, Zhou W, Rupprecht J, Lim L, Thomas-Hall SR, Doebbe A, et al. The metabolome of Chlamydomonas reinhardtii following induction of anaerobic $\mathrm{H}_{2}$ production by sulfur depletion. J Biol Chem. 2009;284(35):23415-25.

53.• Blaby IK, Glaesener AG, Mettler T, Fitz-Gibbon ST, Gallaher SD, Liu B, et al. Systems-level analysis of nitrogen starvation-induced modifications of carbon metabolism in a Chlamydomonas reinhardtii starchless mutant. Plant Cell. 2013;25(11):4305-23. A very well performed transcriptomics study that has made use of a starch-less mutant to understand key components in carbon flux during carbon storage metabolism.

54. Kropat J, Hong-Hermesdorf A, Casero D, Ent P, Castruita M, Pellegrini M, et al. A revised mineral nutrient supplement increases biomass and growth rate in Chlamydomonas reinhardtii. Plant $\mathrm{J}$. 2011;66(5):770-80.

55. Siaut M, Cuine S, Cagnon C, Fessler B, Nguyen M, Carrier P, et al. Oil accumulation in the model green alga Chlamydomonas reinhardtii: characterization, variability between common laboratory strains and relationship with starch reserves. BMC Biotechnol. 2011;11:7.

56. Rodolfi L, Zittelli GC, Bassi N, Padovani G, Biondi N, Bonini G, et al. Microalgae for oil: strain selection, induction of lipid synthesis and outdoor mass cultivation in a low-cost photobioreactor. Biotechnol Bioeng. 2009;102(1):100-12.

57. Wang ZT, Ullrich N, Joo S, Waffenschmidt S, Goodenough U. Algal lipid bodies: Stress induction, purification, and biochemical characterization in wild-type and starchless Chlamydomonas reinhardtii. Eukaryot Cell. 2009;8(12):1856-68. 
58. Goodenough U, Blaby I, Casero D, Gallaher SD, Goodson C, Johnson S, et al. The path to triacylglyceride obesity in the sta6 strain of Chlamydomonas reinhardtii. Eukaryot Cell. 2014;13(5): 591-613. Following on from the Blaby et al. 2013 study, this paper performs further interesting transcriptomic analysis on a starchless mutant but also looks at the importance of acetate assimilation.

59. Toepel J, Illmer-Kephalides M, Jaenicke S, Straube J, May P, Goesmann A et al. New insights into Chlamydomonas reinhardtii hydrogen production processes by combined microarray/RNA-seq transcriptomics. Plant Biotechnol J. 2013;11(6):717-33. Another use of transcriptomics to gain further understanding of $\mathrm{H}_{2}$ generation

60. Schroda M, Beck CF, Vallon O. Sequence elements within an HSP70 promoter counteract transcriptional transgene silencing in Chlamydomonas. Plant J. 2002;31(4):445-55.

61. Kilian O, Benemann CSE, Niyogi KK, Vick B. High-efficiency homologous recombination in the oil-producing alga Nannochloropsis sp. Proc Natl Acad Sci U S A. 2011;108(52): 21265-9. The ability of this green algae to perform efficient nuclear genome homologous recombination is interesting as a fundamental observation in its own right but the potential for targeted manipulation of this organism should have many applied benefits.

62. Liu W, Yuan JS, Stewart Jr CN. Advanced genetic tools for plant biotechnology. Nat Rev Genet. 2013;14(11):781-93.

63. Sizova I, Greiner A, Awasthi M, Kateriya S, Hegemann P. Nuclear gene targeting in Chlamydomonas using engineered zinc-finger nucleases. Plant J. 2013;73(5):873-82. Another interesting advance in genome engineering for an organism that does not show an efficient nuclear genome homologous recombination.

64. Work VH, Radakovits R, Jinkerson RE, Meuser JE, Elliott LG, Vinyard DJ, et al. Increased lipid accumulation in the Chlamydomonas reinhardtii sta 7-10 starchless isoamylase mutant and increased carbohydrate synthesis in complemented strains. Eukaryot Cell. 2010;9(8):1251-61.

65. Leon-Banares R, Gonzalez-Ballester D, Galvan A, Fernandez E. Transgenic microalgae as green cell-factories. Trends Biotechnol. 2004;22(1):45-52.

66. Msanne J, Xu D, Konda AR, Casas-Mollano JA, Awada T, Cahoon $\mathrm{EB}$, et al. Metabolic and gene expression changes triggered by nitrogen deprivation in the photoautotrophically grown microalgae Chlamydornonas reinhardtii and Coccomyxa sp. C-169. Phytochemistry. 2012;75:50-9.

67. Chen JE, Smith AG. A look at diacylglycerol acyltransferases (DGATs) in algae. J Biotechnol. 2012;162(1):28-39.

68. La Russa M, Bogen C, Uhmeyer A, Doebbe A, Filippone E, Kruse $\mathrm{O}$, et al. Functional analysis of three type-2 DGAT homologue genes for triacylglycerol production in the green microalga Chlamydomonas reinhardtii. J Biotechnol. 2012;162(1): 13-20. One of the first studies to functionally characterise DGAT genes from Chlamydomonas but with the unexpected result that over-expression of the genes did not yield a lipid phenotype.

69. Gong Y, Zhang J, Guo X, Wan X, Liang Z, Hu CJ, et al. Identification and characterization of PtDGAT2B, an acyltransferase of the DGAT2 acyl-coenzyme A: diacylglycerol acyltransferase family in the diatom Phaeodactylum tricornutum. FEBS Lett. 2013;587(5):481-7.

70. Cui Y, Zheng G, Li X, Lin H, Jiang P, Qin S. Cloning and characterization of a novel diacylglycerol acyltransferase from the diatom Phaeodactylum tricornutum. J Appl Phycol. 2013;25(5): 1509-12.

71. Niu Y-F, Zhang M-H, Li D-W, Yang W-D, Liu J-S, Bai W-B, et al. Improvement of neutral lipid and polyunsaturated fatty acid biosynthesis by overexpressing a Type 2 diacylglycerol acyltransferase in marine diatom Phaeodactylum tricornutum. Mar Drugs. 2013;11(11):4558-69.
72.• Trentacoste EM, Shrestha RP, Smith SR, Gle C, Hartmann AC, Hildebrand $\mathrm{M}$, et al. Metabolic engineering of lipid catabolism increases microalgal lipid accumulation without compromising growth. Proc Natl Acad Sci U S A. 2013;110(49):19748-53. A very interesting metabolic engineering approach to manipulate lipid breakdown by the degradation of a lipase gene yielding a significant increase in lipid productivity.

73. Dubini A, Ghirardi M. Engineering photosynthetic organisms for the production of biohydrogen. Photosynthesis Res. 2014. doi:10.1007/s11120-014-9991-x.

74. Lin H-D, Liu B-H, Kuo T-T, Tsai H-C, Feng T-Y, Huang C-C, et al. Knockdown of PsbO leads to induction of HydA and production of photobiological $\mathrm{H}_{2}$ in the green alga Chlorella sp. DT Bioresour Technol. 2013;143:154-62.

75. Tolleter D, Ghysels B, Alric J, Petroutsos D, Tolstygina I, Krawietz $\mathrm{D}$, et al. Control of hydrogen photoproduction by the proton gradient generated by cyclic electron flow in Chlamydomonas reinhardtii. Plant Cell. 2011;23(7):2619-30.

76. Volgusheva A, Styring S, Mamedov F. Increased photosystem II stability promotes $\mathrm{H} 2$ production in sulfur-deprived Chlamydomonas reinhardtii. Proc Natl Acad Sci USA. 2013;110(18):7223-8. A novel approach to enhance $\mathrm{H}_{2}$ production through the manipulation of photosynthetic state transitions.

77. Oey M, Ross IL, Stephens E, Steinbeck J, Wolf J, Radzun KA, et al. RNAi knock-down of LHCBM1, 2 and 3 increases photosynthetic $\mathrm{H}_{2}$ production efficiency of the green alga Chlamydomonas reinhardtii. PLoS One. 2013;8(4):e61375.

78. Mussgnug JH, Thomas-Hall S, Rupprecht J, Foo A, Klassen V, McDowall A, et al. Engineering photosynthetic light capture: impacts on improved solar energy to biomass conversion. Plant Biotechnol J. 2007;5(6):802-14.

79. Flynn KJ, Greenwell HC, Lovitt RW, Shields RJ. Selection for fitness at the individual or population levels: modelling effects of genetic modifications in microalgae on productivity and environmental safety. J Theor Biol. 2010;263(3):26980 .

80. Flynn KJ, Mitra A, Greenwell HC, Sui J. Monster potential meets potential monster: pros and cons of deploying genetically modified microalgae for biofuels production. Interface Focus. 2013;3(1): 20120037. Modelling of GM strain fitness highlights some of the potential environmental impacts of strain engineering and indicates careful regulation on the use of GM algae.

81. Sheehan J, Dunahay T, Benemann J, Roessler P. A look back at the U.S. Department of Energy's aquatic species program: biodiesel from algae: National Renewable Energy Laboratory, 1998. Report No.: NREL/TP-580-24190.

82. Mutanda T, Ramesh D, Karthikeyan S, Kumari S, Anandraj A, Bux F. Bioprospecting for hyper-lipid producing microalgal strains for sustainable biofuel production. Bioresour Technol. 2011;102(1): 57-70.

83. Zhou W, Li Y, Min M, Hu B, Chen P, Ruan R. Local bioprospecting for high-lipid producing microalgal strains to be grown on concentrated municipal wastewater for biofuel production. Bioresour Technol. 2011;102(13):6909-19.

84. Elliott LG, Feehan C, Laurens LML, Pienkos PT, Darzins A, Posewitz MC. Establishment of a bioenergy-focused microalgal culture collection. Algal Res. 2012;1(2):102-13.

85. Dean AP, Sigee DC, Estrada B, Pittman JK. Using FTIR spectroscopy for rapid determination of lipid accumulation in response to nitrogen limitation in freshwater microalgae. Bioresour Technol. 2010;101(12):4499-507.

86. Wu HW, Volponi JV, Oliver AE, Parikh AN, Simmons BA, Singh $\mathrm{S}$. In vivo lipidomics using single-cell Raman spectroscopy. Proc Natl Acad Sci U S A. 2011;108(9):3809-14.

87. Manandhar-Shrestha K, Hildebrand M. Development of flow cytometric procedures for the efficient isolation of improved lipid 
accumulation mutants in a Chlorella sp. microalga. J Appl Phycol. 2013;25(6):1643-51.

88. Comai L, Young K, Till BJ, Reynolds SH, Greene EA, Codomo $\mathrm{CA}$, et al. Efficient discovery of DNA polymorphisms in natural populations by ecotilling. Plant J. 2004;37(5):778-86.

89. Ma Y, Wang Z, Zhu M, Yu C, Cao Y, Zhang D, et al. Increased lipid productivity and TAG content in Nannochloropsis by heavy-ion irradiation mutagenesis. Bioresour Technol. 2013;136:360-7.

90. Cagnon C, Mirabella B, Hoa Mai N, Beyly-Adriano A, Bouvet S, Cuine $S$, et al. Development of a forward genetic screen to isolate oil mutants in the green microalga Chlamydomonas reinhardtii. Biotechnol Biofuels. 2013;6:178.
91. Bougaran G, Rouxel C, Dubois N, Kaas R, Grouas S, Lukomska E, et al. Enhancement of neutral lipid productivity in the microalga Isochrysis affinis galbana (T-Iso) by a mutation-selection procedure. Biotechnol Bioeng. 2012;109(11):2737-45.

92. Carrier G, Garnier M, Le Cunff L, Bougaran G, Probert I, De Vargas $\mathrm{C}$, et al. Comparative transcriptome of wild type and selected strains of the microalgae Tisochrysis lutea provides insights into the genetic basis, lipid metabolism and the life cycle. PLoS One. 2014;9(1):e86889. An interesting study that has used transcriptomics to explain the lipid productivity increase in a random mutagenised strain. A large number of genes were altered relative to the wild type but surprisingly very few directly involved in lipid metabolism. 